\title{
Magnet Software Based Fault Analysis of Induction Motor Using Finite Element Analysis
}

\author{
K. Mohanraj ${ }^{1}$, Aditi Mohapatra ${ }^{2}$, Dr. S. S. Dash ${ }^{3}$ and Arun Noyal Doss ${ }^{4}$ \\ ${ }^{I}$ Asst. Professor, Department of Electrical \& Electronics Engineering, SRM University, Tamil Nadu, India \\ ${ }^{2} P G$ scholar, Department of Electrical \& Electronics Engineering, SRM University, Tamil Nadu, India \\ ${ }^{3}$ Department Head, Department of Electrical \& Electronics Engineering, SRM University, Tamil Nadu, India \\ ${ }^{4}$ Asst. Professor, Department of Electrical \& Electronics Engineering, SRM University, Tamil Nadu, India
}

\begin{abstract}
Induction motor is one of the most commonly preferred motors used in the industry due to its long life \& rugged construction. Faults occurring in an induction motor can significantly affect the performance of the motor and the drive which is running it. This project aims to study \& analyze the faults which can occur internally in an induction motor .To implement fault analysis first the machine is modeled using MAGNET software. The motor is studied under healthy conditions. Subsequently faults are introduced \& fault analysis is carried out. In the model of induction rotor bars are broken and the study is mostly based on magnetic field analysis of the motor under healthy conditions \& under faulty conditions. The variation of starting torque with respect to increasing number of broken rotor bars is studied and a graph was plotted to show the variation.
\end{abstract}

Keywords: MAGNET Software, Finite Element Analysis, Magnetic Field Intensity.

\section{Introduction}

Motors convert electrical energy to mechanical energy by the interaction of magnetic fields set up by in the stator \& rotor windings. All the four motors have the same operating components: stator (stationary parts), rotor (rotating parts), bearings \& enclosure. The name induction motor arises from the nature of the developed torque. Torque is developed when voltage is applied to the stator and current begins to flow in the stator windings.

The stator winding currents produce a magnetic field that rotates in a counterclockwise direction. The changing magnetic field of the stator induces electromotive force in the rotor cage winding. The induced emf causes current to flow and magneto motive force in the rotor windings. In turn the rotor mmfs produce a magnetic flux pattern which also rotates in the air gap at the same speed as the stator winding field. Induction motors are the most commonly used prime movers in industrial applications. They are best suited for constant speed applications. Speed control can also be done with the help of power converter circuits. The 3-phase squirrel cage induction motor is the workforce of the industry as it is rugged \& reliable.

The interaction between the primary field and secondary currents produces torque from zero rotor speed onwards. The rotor speed at which the rotor currents are zero is called ideal no-load or synchronous speed. The rotor windings may be multiphase (wound motors) or made of bars short-circuited by end rings (cage rotors). All primary and secondary windings are placed in the uniform slots stamped into thin silicon steel sheets called laminations. The induction machine has a rather uniform air gap of 0.2 to $3 \mathrm{~mm}$. The secondary windings may be short circuited or connected to an external impedance or to a power source of variable voltage and frequency.

Induction motors are the most commonly used prime movers in industrial applications. They are best suited for constant speed applications. Speed control can also be done with the help of power converter circuits. The 3-phase squirrel cage induction motor is the workforce of the industry as it is rugged \& reliable. Electrical related faults are frequently occurring faults in three-phase induction machine which will produce more heat on both stator and rotor winding. This leads to the reduction the life time of induction machine.

Stator winding fault in Induction Motors can be detected using Unknown Input Observer (UIO) \& Extended Kalman Filter methods. They are used for speed estimation and fault detection methods respectively[1].Using analysis of permeance and MMF harmonics, frequency of air gap flux density harmonics which occur due to irregularities are calculated. It helps in detecting faulty ball bearing conditions [2]. A procedure for electromagnetic design of three phase Induction Motor is discussed. This procedure is based on self-consistent equations. The electrical and magnetic properties are imposed by the user but the geometric dimensions are automatically calculated [3].The choice between Copper rotor bars and fabricated Aluminum rotor bars is discussed and debated. The fundamentals of rotor construction and basic information on how the Induction Motor works are discussed [10]. The new IEC standard which defines the stator winding insulation requirement when the Induction Motor operates with Adjustable frequency drives (AFDs) is discussed. The 
magnetic noise that may be generated if higher frequency voltage harmonics are present in the AFD is minimized.

This paper discusses the designing of healthy 1HP Three Phase Induction Motor using MAGNET software. Subsequently the variation of starting torque is studied once broken rotor bar fault is introduced using MAGNET software.

\section{Designing The Three Phase Induction Motor Using Magnet Software}

Designing the induction motor consists of designing the stator, rotor, ball bearings, end rings \& shaft. The stator consists of the stator core \& winding. Stator core is made up of laminated sheet steel of thickness of $0.5 \mathrm{~mm}$. The stator core internal diameter \& length are the main dimensions of the induction motor. All the values of the diameter \& length have been by measuring them from a real induction motor .Hence the respective values for diameters of different parts are:

1. Stator frame- $600 \mathrm{~mm}$

2. Stator Bore- $460 \mathrm{~mm}$

3. Rotor- $324 \mathrm{~mm}$

4. Shaft-1mm

5. Ball bearings $-2.2 \mathrm{~mm}$

6. End Rings-3mm formulae:

The length of the motor has been assumed to be $40.5 \mathrm{~mm}$. Air gap can be calculated from the following

1. $\mathrm{Lg}=0.2+2\left[(\mathrm{DL})^{\wedge} 1 / 2\right]$ in $\mathrm{mm}$ where $\mathrm{Lg}$-air gap, $\mathrm{D}=$ Diameter of the stator bore $\& \mathrm{~L}=$ Length of the motor.

2. $\mathrm{Lg}=0.2+\mathrm{D}$ in $\mathrm{mm}$ where $\mathrm{D}$ is the diameter of the stator.

Rotor core is made up of laminated sheet steel of thickness $0.5 \mathrm{~mm}$. The Copper bars \& end rings are directly casted over the rotor core. The current rating assigned=7.5Amperes \& Number of conductors $=100$. When Copper is employed, the rotor bars are inserted on the slots from the end of the rotor \& end-rings are joined to them by bracing. Cold Rolled Stainless Steel is used as design material for stator, rotor, and ball bearing. Aluminium is used for the construction of end ring. The bars used in the rotor are made up of Copper \& are skewed. The conductors used are also made up of copper.

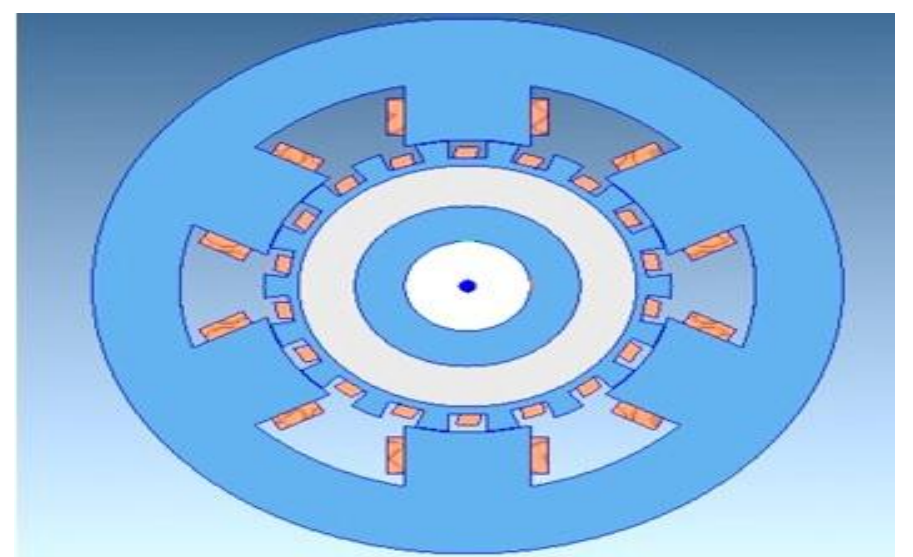

Fig 1: Designed Model of Three Phase Induction Motor Using MAGNET

Fig.1. shows the front view of induction motor which has been designed with the help of MAGNET software. It consists of a stator, rotor, end rings, ball bearings, \& shaft in the decreasing order of the radius. The orange-coloured rectangular structures around the shaft depict the windings. Phase-excitation has been given to only 1 of the phases which can be seen as a small dot on 1 of the winding \& a small cross on the other winding. They depict the entering \& leaving of the current in the coil respectively. The orange-coloured structures on the rotor depict the skewed Copper bars. The X \& Y coordinate axis is in meters. 


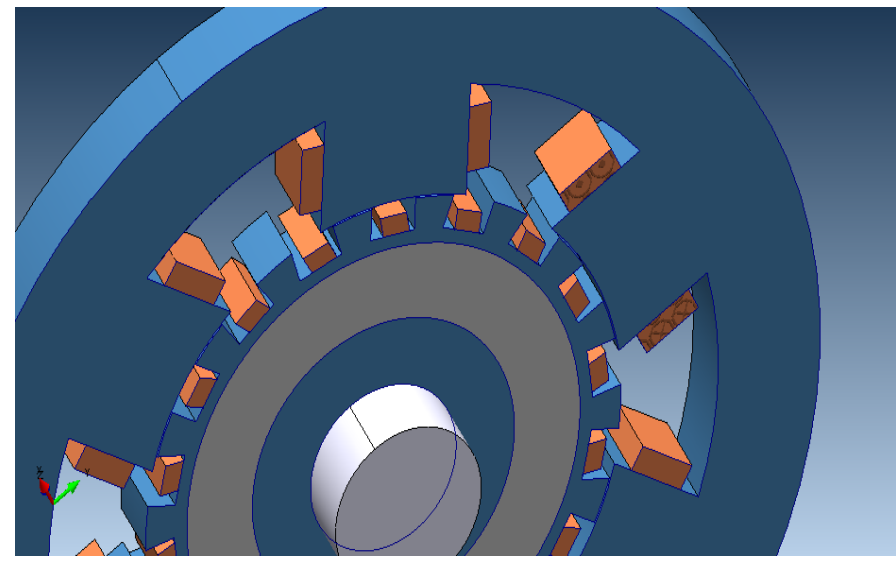

Fig.2.Close View of the Induction Motor

Fig.2. shows a close view of the induction motor modelled using MAGNET software. Shaft is denoted by the white coloured cylindrical structure protruding outside.

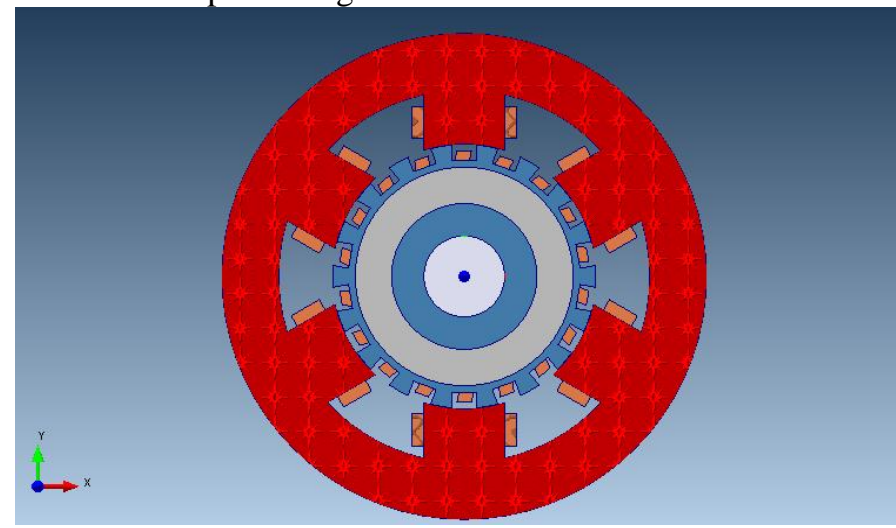

Fig. 3. Checking leakage of modeled induction motor

In MAGNET software an area depicted by the deep-red colour shown above is a proof that the component doesn't have any holes or leakage. In the above figure it means the stator component is perfectly designed and it doesn't have any leakages or air gap. Similarly the accuracy of the design of all the components was verified by implementing the features of the MAGNET software to all other parts.

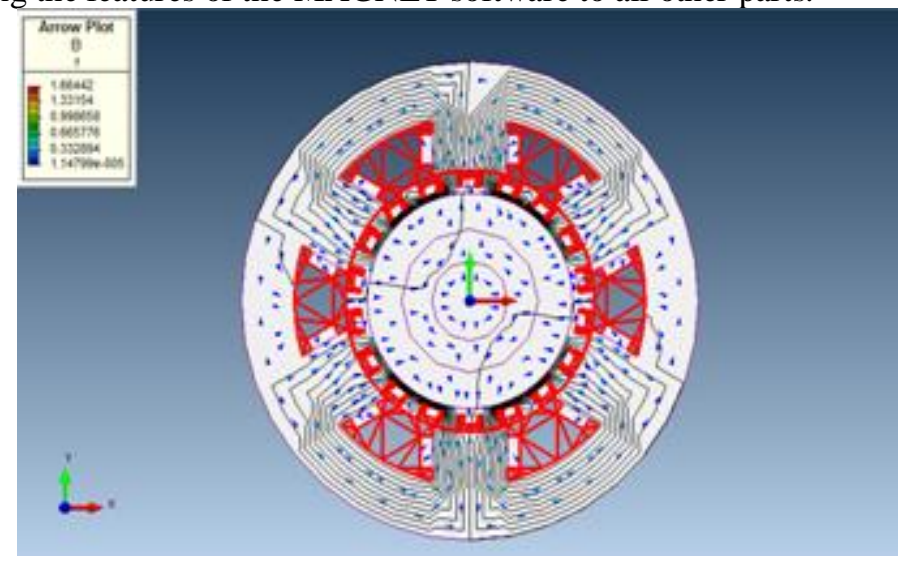

Fig. 4. Arrow Plot of the Field created

Fig.4. depicts the arrow plot of the magnetic field lines. The red colored lines show heavy magnetization while the blue color arrows show relatively weak magnetization. The direction of the magnetic field is in accordance with the polarity of the excitation. The left-hand side pole windings are given positive excitation \& the right-hand side pole windings have been given negative polarity. Hence one can clearly see the magnetic flux lines rotating in an anticlockwise direction. The magnetic field is the strongest near the stator poles and then on the rotor slots. This observation is in accordance with the working principles of an induction motor 


\section{The Finite Element Analysis Approach}

In order to implement the model, we are using MAGNET software. MAGNET software differs in its approach when it comes to conventional machine design with respect to the fact that it uses finite element analysis. It is due to the fact that there are several limitations of the conventional machine design. The conventional methods of design are based on the assumed flux path method for the determination of the flux distribution inside machine. They use analytical formulae based on lumped parameters estimated using linear magnetic circuit model. The machines are assumed to have infinitely deep rectangular slots and the core of the machine is operated under saturated condition. These assumptions may not be suitable in present day design of Electrical Machines with complex geometries and material non-linearity. The key limitation of magnetic circuits or permeance method is that it requires assumptions of the magnetic flux path. The length of the cross-sectional areas of all the paths must be known. Usually they are assumed to consist of straight lines, which is erroneous. There are situations where analytical solution is difficult. For instance, in irregular problem region, it is mathematically impossible to describe boundaries. Configuration may be composed of several different materials whose regions are mathematically difficult to describe.

In finite element analysis, the software requires no assumption of flux path or related empirical factors. It accurately calculates magnetic fields and related motor design parameters for motors of complicated geometries with saturation and/permanent magnets. The finite element analysis is a numerical computation method which derives its name from finite elements into which the region is partitioned.

In finite element analysis based variational approach; field problem is formulated in terms of a variational expression called energy functional. This expression can be identified with energy stored in a system. Minimization of the energy functional leads to Euler's equation which is the partial differential equation describing the field. A function is searched that minimizes the energy functional directly instead of attempting to solve the differential equation. Natural boundary conditions (Dirichlet or homogeneous Neumann boundary) are inherent in functional formulation.

In order to implement the variational approach by means of numerical computations, the continued functions representing exact solution is approximated by functions defined over each of the discrete sub regions into which the field is subdivided. The resulting system of equations is small enough to permit the use of very rapidly converging solution techniques.

The system of equations which govern the process of finding out the exact solution using finite element analysis are:

$$
\begin{aligned}
& A=\frac{(\mu \div 4 \pi) \varphi d l}{r} \\
& \frac{\partial}{\partial x}\left(\gamma \frac{\partial A}{d x}\right)+\frac{\partial}{\partial y}\left(\gamma \frac{\partial A}{d y}\right)=-J \\
& F=\iint_{R}\left(\int_{0}^{B} \gamma \cdot b \cdot d b\right) d a-\iint_{R} J \cdot A \cdot d a
\end{aligned}
$$

Where A is the Magnetic Vector Potential, $\mu$ is the permeability of the magnetic material, 1 is length of the homogeneous conductor is the radius vector from the axes to the conductor. J denotes the current density; B, $\mathrm{b}$ denote the magnetic field while $\mathrm{H}$ denotes the magnetic field intensity. $\oint$ represents the closed loop integral of the enclosed function.

The application of the finite element method in the design of electrical machines is proficient in the determination of important design parameters, such as flux linkages, induced voltages, core losses, winding inductances and electromagnetic torque developed, with a very high accuracy.

\subsection{Flux Plots}

Prediction of flux distribution is very useful for the design process. It gives the status of magnetic saturation throughout the machine as well as the ratio of leakage to useful flux in various parts of the magnetic circuit. Once the value of the vector potential has been determined at each node, the flux distribution is plotted as shown in Fig.7.Assuming that $\mathrm{z}$ is the direction of currents, the vector potential has only one component in $\mathrm{z}$ direction, and the magnetic field $B$ is given by:

$$
B=\nabla \times A
$$




$$
\nabla \times A=\frac{\partial A}{\partial Y} * x_{0}+\frac{\partial A}{\partial X} * y_{0}
$$

\subsection{Calculation of Flux Linkages}

Consider one pole of the motor carrying a concentrated winding. The flux that is linked by a representative turn of a coil can be expressed in terms of the flux density B and the area enclosed by the coil. Thus,

$$
\phi=\int B \cdot d S
$$

The expression for the flux will be:

$$
\phi=\int(\nabla \times A) \cdot d S
$$

Using Stroke's Theorem,

$$
\phi=\int A \cdot d l
$$

where the integration is around the closed contour of the coil.

Since the length of the winding in the axial direction is always greater than the distance between the coil sides, the end contribution in the integral may be neglected. If the vector potential on the right and left hand coil sides of the coil is denoted as $\mathrm{A}_{\mathrm{R}}$ and $\mathrm{A}_{\mathrm{L}}$ respectively, then the flux will be:

$$
\phi=l\left(A_{R}-A_{L}\right)
$$

where $l$ is the core length. For a multi turn coil having $\mathrm{N}$ turns, the flux linkages are:

$$
\psi=N \phi=N l\left(A_{R}-A_{L}\right)
$$

If the current carried by each conductor of the winding is $i$, then the inductance of the winding will be:

$L=\frac{N \phi}{i}=\frac{N l\left(A_{R}-A_{L}\right)}{i}$

At this point, non-linear continuum problem represented by Equation (1), Equation (2) \& Equation (3) will be reduced to a set of non-linear algebraic equations. The most common solution method is the NewtonRaphson (N-R) algorithm and the resulting set of equations is solved by Gaussian elimination. The N-R algorithm starts from an assumed value for the reluctivity $\gamma$ and proceeds by means of iterations. In each iteration, $\gamma$ is updated with respect to the B-H characteristics of the material.

\section{Analysis Of Healthy Three Phase Induction Motor}

After the three phase motor was designed, it was simulated in 2D. The resultant magnetic field intensity plot was obtained and analyzed.

The resultant field circle graph shows the magnetic field intensity at a radius of $160 \mathrm{~mm}$ from the centre at various points around the circle. From point 0 to $0.05, \mathrm{H}$ is highest as this part of the rotor comes directly under the stator and is the slot area of the rotor. Just as it reaches the edge of the rotor pole, it becomes 0 . It remains 0 from 0.05 to 0.1 as some of the part of this region falls in the air gap and most of the field lines pass through this region due to low reluctance.

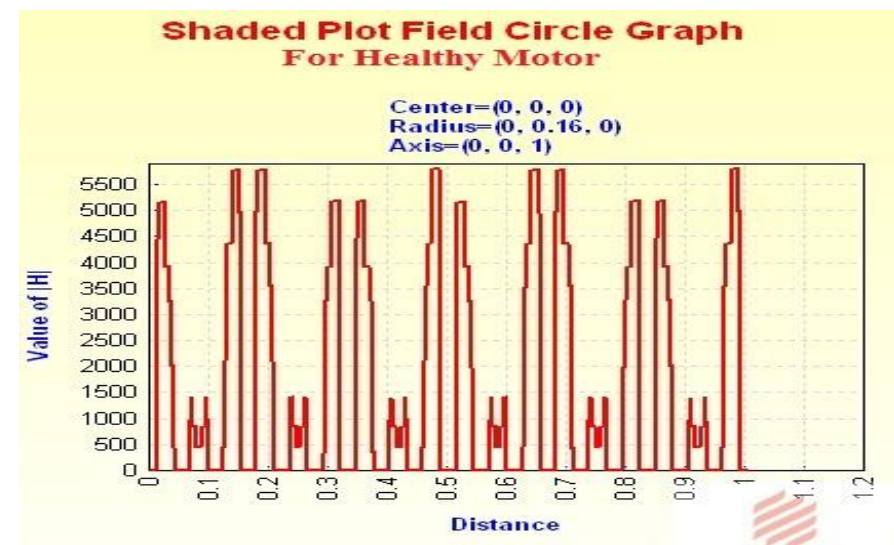

Fig. 5. Variation of Magnetic Field Intensity with Radii for Healthy Motor 
The breaks in the peaks arise due to the positioning of the rotor copper bars with respect to the stator poles. When they are perfectly aligned, the field intensity is less compared to when they are just moving out of the influence of 1 stator pole \& entering the influence of the second. The torque value was calculated to be $15.92 \mathrm{Nm}$ under healthy conditions.

\section{Analysis Of Three Phase Induction Motor With Broken Rotor Bars}

Out of 18 rotor bars, four bars were broken in the new design to introduce broken rotor bars fault. The design is shown in Fig. 6. The black slots represent the slots where four rotor bars are broken. The plot of magnetic field intensity with respect to various points on the circle of a radius $160 \mathrm{~mm}$ was plotted. The point $160 \mathrm{~mm}$ from the centre was chosen and it lies on the rotor.

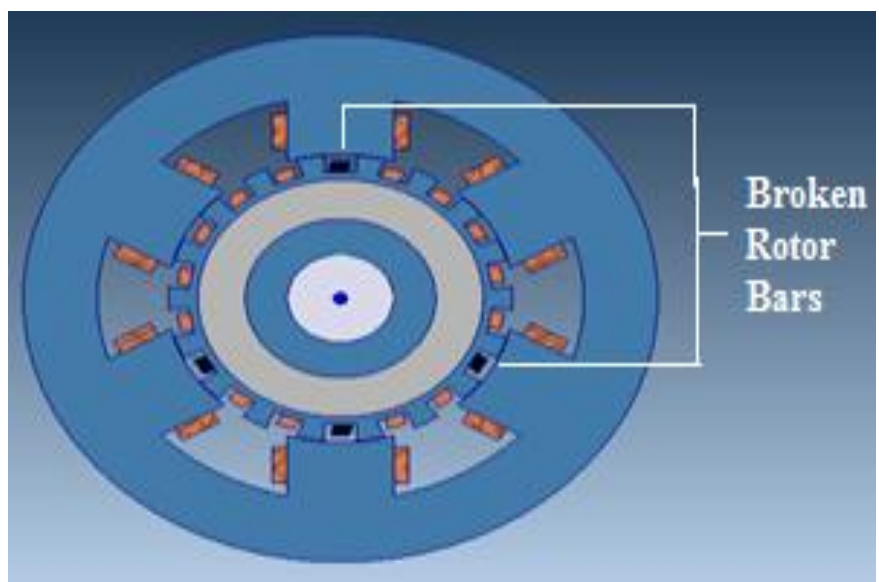

Fig. 6. Induction Motor with 4 Broken Bars

From Fig.7 some clear observations can be made. Firstly, the overall nature of the graph doesn't change; the graph still has peaks \& troughs like the previous plot of healthy motor. However, there are more breaks in the waveform. The waveform becomes more distorted due to the uneven magnetic fields caused due to the broken bars. The second observation that can be made is that the value of the magnetic field intensity drops as the flux linking the rotor from the stator drops due to interference from the broken bars. The magnitude drops considerably; it reduces by almost a factor of 1.5 .

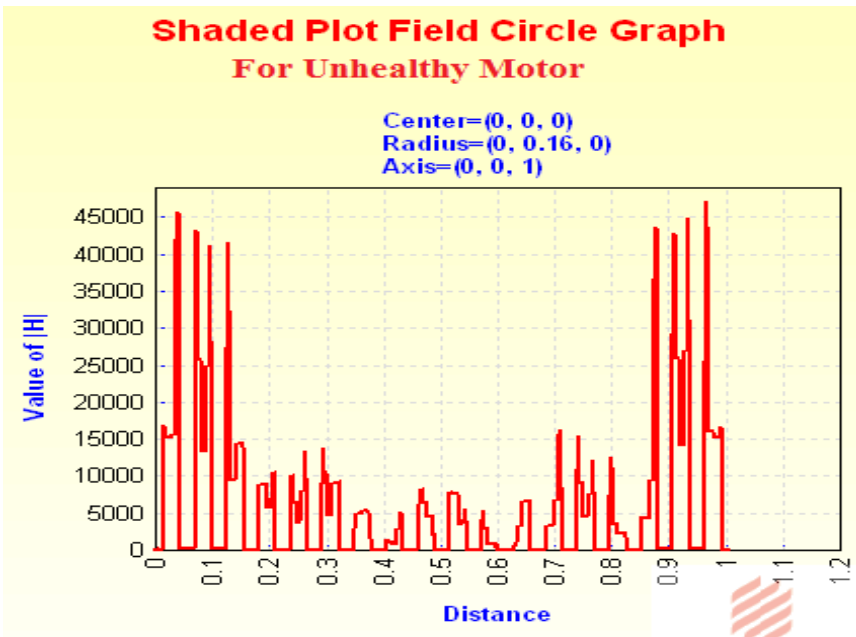

Fig. 7. Variation of Magnetic Field Intensity for Unhealthy Motor.

A similar change in design was made with $9 \& 15$ broken bars. The discretization plots showed errors as the magnetic fields became disturbed. The torque was calculated in all the three cases: with four broken bars, nine broken bars \& with fifteen broken bars \& inferences were drawn from the results. Fig. 8 shows the designed model of the induction motor with 9 broken bars. Fig. 9 shows a graph plotted taking values from Table I. 


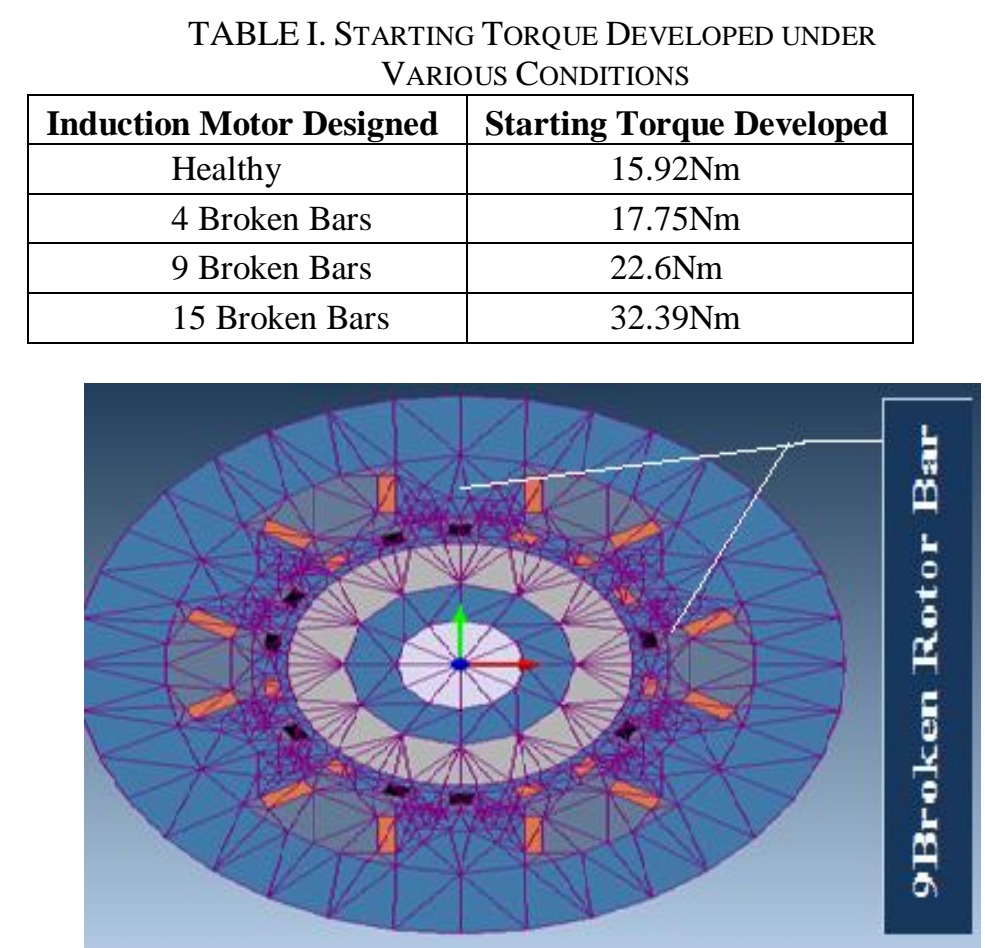

Fig. 8. Three Phase Induction Motor with 9 Broken Bars

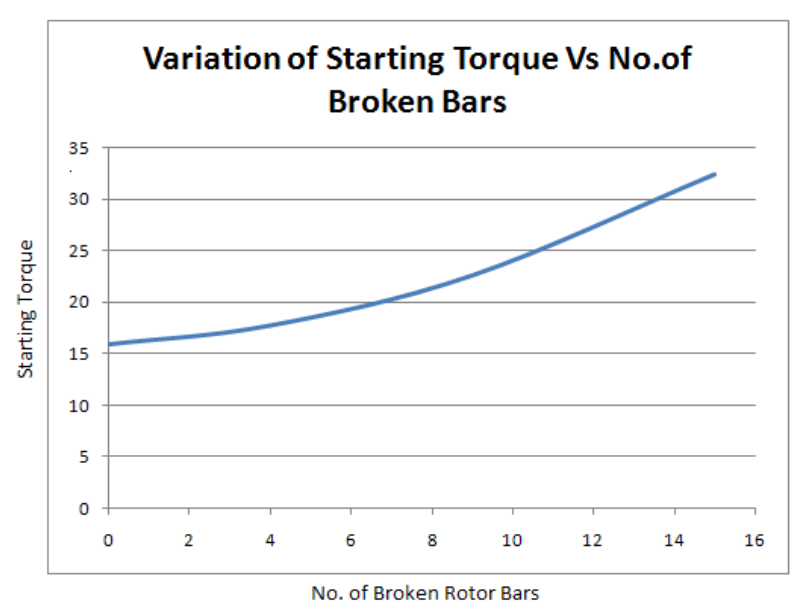

Fig. 9. Plot Showing the Variation of Starting Torque with Number of Broken Bars

\section{Conclusion}

A healthy three phase induction motor was designed using MAGNET software. Its magnetic field intensity was analyzed near the rotor bars. Afterwards, changes in the design were made. Rotor bars were broken-first 4 , then $9 \&$ then 15 . Magnetic field intensity was shown to decrease and the waveform started becoming more distorted. The torque under starting conditions increased with the increase in the number of damaged broken bars. Starting torque first increased slowly but as more bars were broken, the slope of the curve became steeper showing higher rate of change of starting torque. This shows that as more \& more bars are damaged, the magnetic field becomes more \& more distorted. Its magnitude decreases. To compensate for the decrease in magnetic field, the motor torque goes on increasing to very high levels which can lead to dangerous oscillations. 


\section{References}

[1] Knight A.M., Bertani S.P.: Mechanical Fault Detection in a Medium Sized Induction Motor Using Stator Current Monitoring, IEEE Transactions on Energy Conversion, Vol.20, No.4, December 2005.

[2] Dorrel D.G., Evans L., Staton D.A., Knight A.M.: Comparison of Permanent Magnet Drive Motor with a Cage Induction Motor Design for a Hybrid Electric Vehicle, The International Power Electronics Conference, 2010.

[3] Dorrel D.G., Combined Thermal and Electromagnetic Analysis of Permanent Magnet and Induction Machines to Aid Calculation, IEEE Transactions on Industrial Electronics, Vol 55, No.10.October 2008, pp.3566-3574.

[4] Ghazal M., Poshtan J., Robust Stator Winding Fault Detection in Induction Motors, $2^{\text {nd }}$ Power Electronics, Drive Systems \& Technologies Conference, 2011.

[5] Vargan L.M, Jatskevich J., Marti J.R., Load Modelling of an Induction Motor Operated with a Variable Frequency Drive, IEEE Electrical Power \& Energy Conference, 2008.

[6] Arabaci H., Bilgin O., Effect of Rotor Faults in Squirrel-CagecInduction Motors on The Torque-Speed Curve, The $19^{\text {th }}$ International Conference on Electrical Machines-ICEM 2010,Rome.

[7] Watson J.F., Paterson N.C., The Development of an Accurate Finite Element Model to Investigate the Factors which Influence the Fault-Indicating Components of Current in Three-Phase Induction Motors, The Ninth International Conference on Electrical Machines and Drives, Conference Publication No.468,pp. 247-252.

[8] Boglietti A., Cavagnino A., Lazzari M., Geometrical Approach to Induction Motor Design, The $33^{\text {rd }}$ Annual Conference of the IEEE Industrial Electronics Society (IECON), Nov 5-8, Taipei, Taiean, pp.149-156.

[9] Nawrocki S., Hao L., Tang X., Modelling and Analysis of Weld Short Faults of Bar-Wound Propulsion IPM Machine, Part2,Phase-to-Phase Short, IEEE Transactions, 2011.

[10] Hayes P.E.,Wood B.M.,Horn D.G., Mechanical Design of Induction Motors Applied on Adjustable Speed Drives, IEEE IAS PCIC Conference Record,1997.

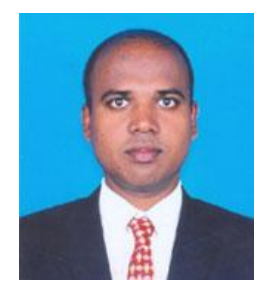

Mr.K.Mohanraj is currently working as Assistant Prof. in SRM University, Chennai. He completed his B.E in Electrical Engineering from Madras University \& M.E. in Power Electronics and Drives from Anna University in 2004\& is currently pursuing his $\mathrm{PhD}$ from SRM University. He has 3 international journal publications\& has presented papers in more than 10 international conferences. His areas of interest include Fault Analysis in Induction Motors, Power Converters \& AC drives.

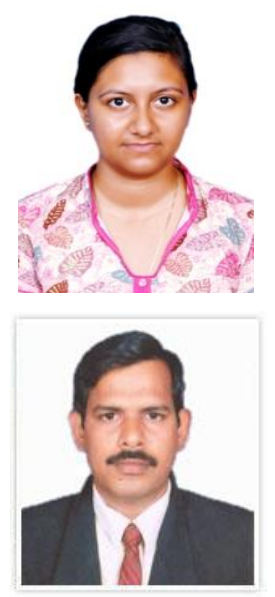

Aditi Mohapatra completed her Bachelor in Technology from Biju Patnaik University of Technology, Odisha, India in Electrical and Electronics Engineering in the year 2010 and is currently a PG Scholar in Power Electronics and Drives from ,SRM University, Chennai, Tamil Nadu, India. Her area of interests include Induction Motor and Synchronous Motor Drives, their control, and Hybrid Electric Vehicles.

Dr.S.S.Dash received the M.E degree in Electrical Engineering from UCE Burla, Orissa, India and $\mathrm{PhD}$ degree in Electrical Engineering from Anna University in 1996 and 2006 respectively. He is presently working as Professor and Head in SRM University Chennai, India. His area of interest includes Power Quality, Inverters, Multilevel Inverters, Power System Operation, Control \& Stability and Intelligent control Techniques.

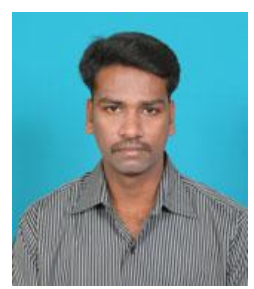

Mr. Arun Noyal Doss was born in India in 1982. He received his B.E in electrical engineering from Madras University in 2004 and M.E from Anna university in 2006. He is currently working towards his $\mathrm{PhD}$ degree in electrical engineering and working as assistant professor in SRM university. His area of interest includes Power Electronics and Special Machines. 